\title{
Degradirana območja organizirane večstanovanjske gradnje med letoma 1945 in 1965 v Sloveniji - metodologija vrednotenja in prenove
}

\begin{abstract}
"Degradirana" stanovanjska območja zavzemajo $9 \%$ deleža urbaniziranih površin petintridesetih, $v$ zadnjih letih planersko raziskanih slovenskih mest. Problematična so predvsem območja organizirane večstanovanjske gradnje, zgrajena do sredine šestdesetih let: izolirana, nevzdrževana, sodobnim standardom neustrezna. Ta raziskava preusmerja dosedanjo abstraktno planersko izhodiščno optiko na konkretno arhitekturno - uporabniško raven. Namenjena je utrditvi ideje o nujnosti prenove oziroma revitalizacije kot edinem možnem reševanja problematike določenega vzorca pozidave, določitvi meril in mer za prenovo ter opredelitvi racionalnih oziroma stvarnih usmeritev za konkretne prispevke $k$ izboljšanju bivalnega standarda, torej k preobratu kulture bivanja v obravnavanem poselitvenem vzorcu.
\end{abstract}

\begin{abstract}
"Degraded" housing areas represent a $9 \%$ share of urbanised surfaces of thirtyfive in planning terms recently researched Slovenian towns. Above all social housing estates built between 1945 and 1965 present issues since they are isolated, poorly maintained, and cannot reach modern standards. The research contemplates the redirecting of the present abstract planning rationales to the real architectural, user level. Further intentions of the reserach are to consolidate ideas about the urgency of renewal as the only possible method of solving problems of a certain pattern of building, to determine criteria and measures for renewal and to determine rational or real directions for concrete contributions for the improvement of the standard of living, in short, to a new shift in living culture of the discussed settlement pattern.
\end{abstract}

\author{
Arhitektura \\ Prenova \\ Stanovanjsko \\ območje \\ Slovenija
}

\section{Uvod: predmet obravnave, problemsko ozadje}

Raziskava [1] je bila namenjena utemeljitvi upravičenosti prenove degradiranih območij organizirane večstanovanjske gradnje med letoma 1945 in 1965 v Sloveniji na ravni arhitekture (in mestnega oblikovanja) $\mathrm{z}$ usmeritvijo v vizijo preobrata $\mathrm{v}$ kulturi bivanja $\mathrm{V}$ obravnavanem poselitvenem vzor$\mathrm{cu}$. Prispevek raziskave je $\mathrm{v}$ preu- smeritvi planerske optike $\mathrm{k}$ arhitekturno-uporabniški.

Temeljni izhodišči sta:

- utemeljitev upravičenosti prenove nasploh (P. Fister idr., 2001) in

- okvir prenove velikih sosesk v Sloveniji z utemeljitvijo upravičenosti s planerskega vidika (K. Dimitrovska Andrews idr., 1999, K. Dimitrovska Andrews, R. Sendi, 2001).

Analiza problemskega ozadja razkriva tako njegovo količinsko kot kakovostno naravo. $\mathrm{V}$ devetodstotnem deležu degradiranih stano- vanjskih območij planersko raziskanih slovenskih mest (Koželj, 1998, str. 75-112) so najbolj problematična območja organizirane večstanovanjske gradnje, zgrajena med letoma 1945 in 1965. Izolirana so $\mathrm{v}$ razmerju do neposrednega mestnega okolja, nevzdrževana kot odsev socialnega okolja in neustrezna sodobnim standardom in priporočilom. Z vidika mestnega oblikovanja prednjačijo problemi pomanjkanja osrediščenosti in povezanosti, neustrezne dostopnosti in hrupa, z vidika arhitekture neracionalna raba energije in nerazpoznavnost, $\mathrm{z}$ vidika gradbeništva pa 
potresna (ne)varnost. Prelomno leto 1965 označuje čas oživljanja privatne iniciative, materializacijo kompleksnejših zasnov (soseske kot organizacijske strukture), ki so dotlej prevladovale na papirju, pestrejša pa postane stavbna tipologija in $\mathrm{z}$ množičnim prehodom $\mathrm{k}$ betonski gradnji tudi tehnologija. Obravnavanih območij iz več razlogov ne moremo preprosto nadomestiti $\mathrm{Z}$ novogradnjami: zaradi njihovega obsega, ker so priče preobrata kulture bivanja med gradnjo, zaradi stanja njihove materialno prostorske strukture danes, predvsem pa zaradi socialnega vprašanja.

Analiza relevantne literature in rezultatov raziskav na mednarodni ravni razkriva usmeritve s področja stanovanjske gradnje, ki se vedno bolj osredotočajo na vrednosti prenove. $\mathrm{Z}$ vidika umestitve oziroma razmestitve naravnih in grajenih omejitev mestnega prostora lahko zasledimo težnjo $\mathrm{k}$ individualizaciji poselitvenih vzorcev in prostorskemu strukturiranju področij skupne uporabe. Vsebinsko-funkcionalni aspekti kažejo usmeritev k zagotavljanju fizične dostopnosti javnega in zasebnega prostora najrazličnejšim uporabnikom in prilagajanju stanovanj sodobnim standardom. Sledi vrsta teženj glede oblik, materialov, konstrukcij in tehnologij: poudarjanje likovne izraznosti, uporaba ekološko neoporečnih in energetsko učinkovitih gradiv (ter njihove zaščite), ki omogočajo bivalno ugodje in zmanjšujejo porabo energije, in prilagajanje strožjim standardom potresne in požarne varnosti. Pomenska raven odkriva racionalizacijo rešitev (ki se stopnjuje $z$ možnostjo faznosti posegov), povečevanje tržne vrednosti okolja oziroma objekta, možnosti identifikacije prostora in »trajnostno « naravnanost rešitev na različnih ravneh oziroma v različnih merilih.

Med slovenskimi raziskavami stanovanjske gradnje v obdobju zadnjih desetih let, ki obravnavajo predvsem planerska vprašanja, os- taja prostor obravnavanih območij na konkretni arhitekturni ravni, podobno kot $\mathrm{v}$ konkretnem prostoru, zanemarjen. Pojavljajo se sicer posamezni ukrepi na ravni arhitekturne prenove posameznih objektov, zgrajenih v 70. letih in v celoti namenjenih prodaji, medtem ko revitalizacija v smislu urbanistično-arhitekturno-konstrukcijske prenove širših območij oziroma celovitosti zasnovanega (naseljenega) območja še ni zaživela tako zaradi neraziskanih realnih prostorskih možnosti kot tudi zaradi lastniških odnosov, socialne strukture in neusklajenih interesov.

Delovno hipotezo, da je mogoče z določenimi arhitekturnimi ukrepi preusmeriti nadaljnjo degradacijo slovenskih povojnih območij večstanovanjske gradnje $\mathrm{v}$ novo kvaliteto, raziskava preverja s sosledjem naslednjih vprašanj:

- Kateri evropski zgledi prenove so uporabni $v$ našem kulturnem prostoru in koliko?

- Kako labko ocenimo stanje obravnavanib območij s strokovnega in uporabniškega vidika?

- Kateri so ukrepi, ki labko omogočijo nov razvojni preobrat, ko gre za konkretno arbitekturno raven prenove?

- Kateri so kriteriji višje ravni upravičenosti prenove?

Vsebinski okvir raziskave zajema torej oris evropskih vplivov na razvoj stanovanjskih območij, zgrajenih med letoma 1945 in 1965 v Sloveni$\mathrm{ji}$, analizo sodobnih primerov prenove, ekstrapolacijo smernic in oceno uporabnosti primerov. Pregledu temeljnih razvojnih značilnosti sledi ocena stanja slovenskih primerov tako s strokovnega stališča kot s stališča stanovalcev. Specifikacija kriterijev za analizo, oceno in načrtovanje, ki so preverjeni v konkretni aplikaciji področja Rakovnika $\mathrm{v}$ Ljubljani, je namenjen opredelitvi kriterijev upravičenosti prenove s konkretnega arhitekturnega vidika. Sklepi vsebujejo diskusijo o poveza- nosti ciljev in ukrepov prenove in opredelitev načrtovalskih usmeritev, ko gre za prenovo obravnavanega poselitvenega vzorca.

\section{Ožji predmeti obravnave (podteme) in metode}

Raziskava obravnava stanovanjsko območje kot celoto, njene elemente (prostorsko-funkcionalne: odprti prostor, zazidavo) in povezave (materialne, nematerialne) s širšim okoljem in znotraj področja; objekte, njihove elemente (likovno-prostorske, funkcionalne, gradbenotehnične) in povezave (vsebinskoprostorske, s področjem kot celoto, znotraj objekta). Na ravneh mestnega oblikovanja, arhitekture in potrebnih posegov $\mathrm{v}$ konstrukcijo se deduktivni pristop dopolnjuje $\mathrm{z}$ induktivnim. Z zgodovinsko metodo so predstavljeni prostor in čas evropskih vplivov in razmere med letoma 1945 in 1965 v Sloveniji, medtem ko ekstrapolacija smernic v sinteznih poglavjih teži $\mathrm{k}$ futurologiji. Analiza evropskih primerov prenove (vključno z referenčnim primerom Dunaja) ter analitičnega dela študije možnosti mikrourbane prenove obravnavanih območij v Sloveniji sledi opisni metodi (študija primerov); statistični pristop na osnovi ankete pa je uporabljen za analizo bivalne kulture $\mathrm{v}$ izbranih stanovanjskih območjih v Ljubljani.

\section{Pregled dela raziskave}

\subsection{Uporabnost evropskih zgledov prenove v slovenskem kulturnem prostoru}

Vrednotenje evropskih primerov arhitekturne in mestno - oblikovalske prenove odkriva tendence tako 
v obravnavi prostora mesta kot njegovih omejitev. Prostor mesta zahteva družbeno-prostorsko povezanost in osrediščenje, ki daje možnost identifikacije, pa naj gre za materialne in nematerialne komunikacije ali pa za prostorska žarišča, ki jim dajejo pečat novi programi. V obravnavi grajene strukture zasledimo iskanje možnosti dopol-
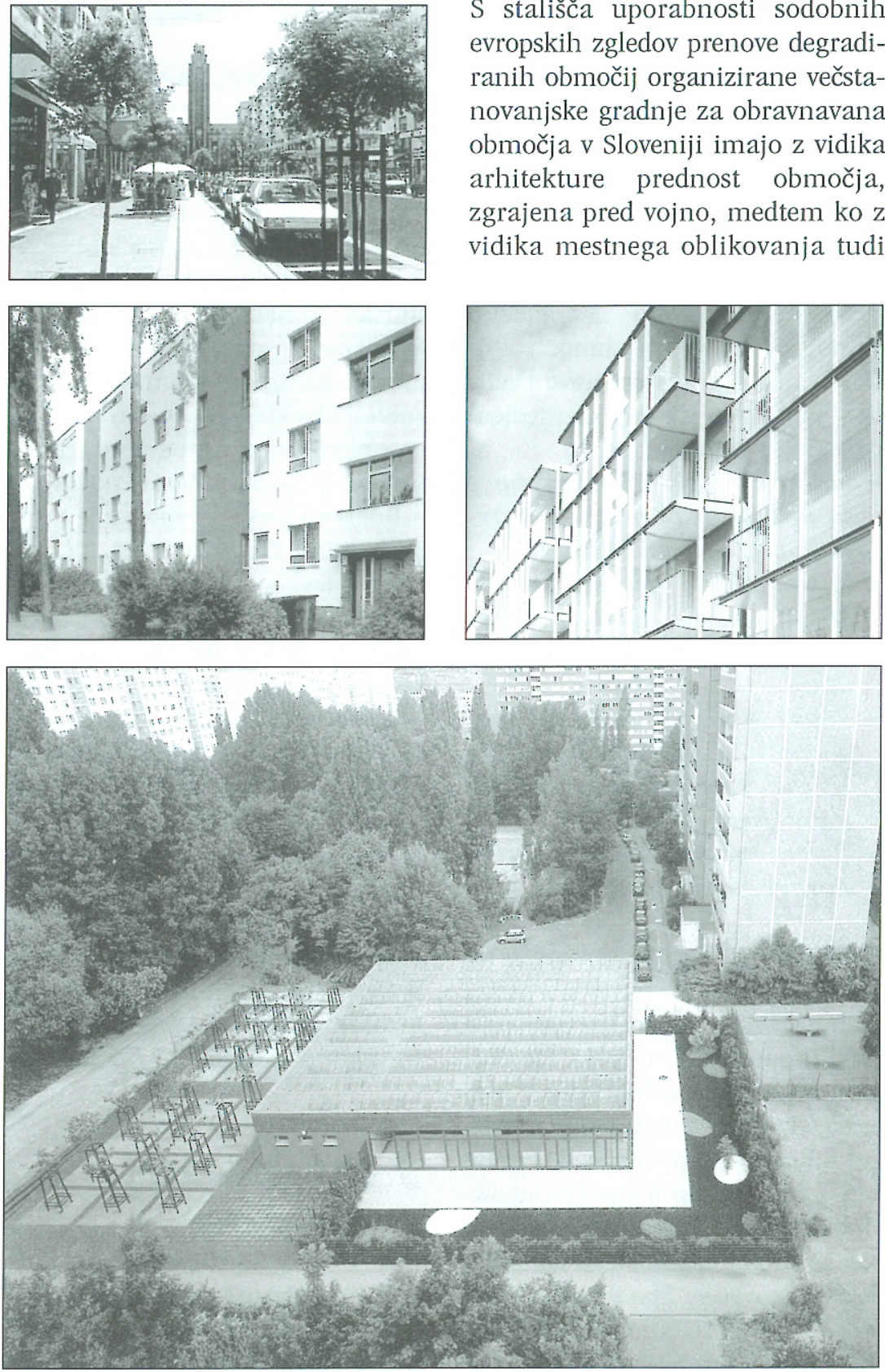

Slika 1: Evropske smernice: povezovanje (Gratte-Ciel, Villeurbanne), individualizacija podobe (Onkel-Tom-Siedlung, Berlin Zehlendorf), tehnične/tehnološke izboljšave (vogal Hauptstasse in Ritterstasse, Dresden), osrediščenje prostora degradiranih stanovanjskih območij (Quartiersplatz, Berlin) (Viri: op. 2)

nitev zazidave. Odločitev o pristopu $\mathrm{k}$ njeni zasnovi in podobi izhaja iz stopnje njene zaščite oziroma spremembe. Sklop tehničnih oziroma tehnoloških izboljšav, ki povečujejo varnost in udobje, postajajo priložnost za razmislek ne le o pristopu $\mathrm{k}$ podobi prostora, ampak tudi o možnih spremembah zazidave. (slika 1 [2])

S stališča uporabnosti sodobnih evropskih zgledov prenove degradiranih območij organizirane večstanovanjske gradnje za obravnavana območja v Sloveniji imajo z vidika arhitekture prednost območja, zgrajena pred vojno, medtem ko z vidika mestnega oblikovanja tudi

\subsection{Razmere v Sloveniji}

Proučitev stanja obravnavanih območij v Sloveniji ima dve izhodiščni optiki: strokovno (arhitektura, urbanistično načrtovanje oziroma oblikovanje) in uporabniško. Območja povojne večstanovanjske gradnje so med gradnjo pomenila preobrat $\mathrm{v}$ načinu bivanja. $\mathrm{V}$ današnji postindustrijski dobi jih s strokovnega stališča vrednotimo kot preživelo, »asocialno« obliko, saj posamezniku ne ponujajo fleksibilnosti bivanja, dela in gibanja $\mathrm{v}$ prostoru. Ideja coniranja ob zasnovi pomeni dandanes zaprtost, izoliranost območij; zunanje ureditve niso vzdrževane, prostor mirujočega prometa ne zadošča potrebam; ločnica med javnim in zasebnim prostorom ne omogoča pestrosti ponudbe skupnih prostorov; dotrajanost ali neustreznost materialov zmanjšuje varnost, ekološko oziroma zdravstveno ustreznost objektov. Potrebno je odstranjevanje oziroma zamenjava elementov; funkcionalna zasnova stanovanj ne ustreza več sodobnemu načinu bivanja; stihijski posegi povzročajo bodisi neenotnost likovne podobe bodisi 
zmanjšujejo varnost objekta, saj se $\mathrm{z}$ dodanimi konstrukcijskimi elementi povečuje teža objektov.

Proučitev možnosti mikrourbane prenove (slika 2 [3]) in primerjava podatkov, pridobljenih z vprašalniki za uporabnike, dokazujejo, da se podobni problemi ne pojavljajo le v »velikih« območjih (K. Dimitrovska Andrews idr., 1999), temveč tudi v območjih z manj kot tisoč prebivalci. Vsebina vprašalnikov spodbuja kritičnost: o odprtem prostoru, stanovanju in spremembah. Med devetsto naključno izbranimi stanovalci v treh ljubljanskih degradiranih območjih povojne organizirane večstanovanjske gradnje (to so: Rakovnik, Litostrojski bloki in Savsko naselje) se je izzivu odzvala tretjina. Višja izobrazba po pričakovanju pogojuje višjo raven zavedanja problemov varnosti in racionalne rabe energije. Uporabniki stanovanj čutijo nujnost preureditev prometnih povezav in parkiranja, fasad, poudarjajo potrebo po večji varnosti in zaščiti pred hrupom. Menijo, da so spremembe potrebne $\mathrm{v}$ vhodnih prostorih in skupnih notranjih hodnikih, medtem ko so funkcionalne zasnove stanovanj zadovoljive (stanovalci so si prostor že prilagodili ali pa so navajeni stanja), nove, potencialno pridobitniške dejavnosti pa niso (stanovalci imajo raje mir ...). (slika 3)

\section{Načrtovalske usmeritve}

\subsection{Ključni cilji in ukrepi arhitekturne prenove}

Prispevek je rezultat prizadevanj, usmerjenih $\mathrm{k}$ bistvenim ciljem arhitekturne prenove obravnavanega poselitvenega vzorca. Na ravni urbanega okolja obravnavanih območij je treba ne le ohraniti, temveč tudi povečati vrednost stanovanj in udobje bivanja (gibanja, zaznavanja) ter izboljšati prilagojenost glo- balnih rešitev lokalnim razmeram. $\mathrm{K}$ preobratu na ravni elementov urbanega okolja prispevajo cilji: izboljšati povezanost, povečati pestrost in usklajenost elementov oziroma sistemov ter zagotoviti varnost. V konkretnem, arhitekturnem prostoru oziroma mestni krajini gre $\mathrm{za}$ iskanje dinamičnega ravnovesja med ohranjanjem in spreminjanjem zasnove oziroma podobe prostora, ki sledi vzpostavljanju ali poudarjanju hierarhije, da bi pove- čali razpoznavnost elementov in povezav. Pomembni cilji so še: izboljšati dostopnost (povečati udobje gibanja), komunalno opremljenost, ponudbo blaga in storitev, povečati prilagodljivost spremembam (fleksibilnost oziroma adaptabilnost zasnove, površino stanovanj), izboljšati splošno varnost (prometno, potresno), uravnati raven mikroklime oziroma ugodja v prostoru (osvetljenosti, zaščititi pred nezaželenimi atmosferskimi vplivi, pred hrupom,
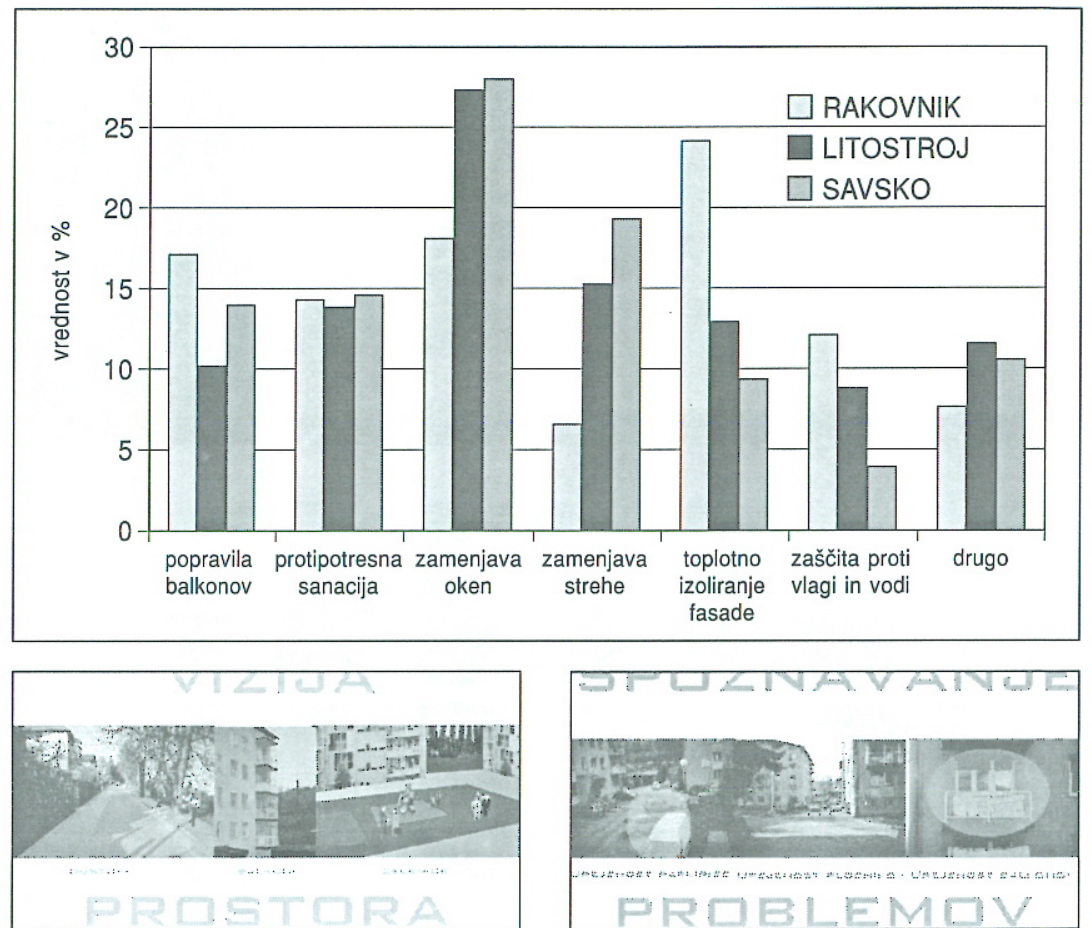

Slika 2: Možnosti mikrourbane prenove stanovanjskih območij, zgrajenih med letoma 1945 in 1965 v Sloveniji (Novo mesto - Mestne njive) (Vira: op. 1, 3)

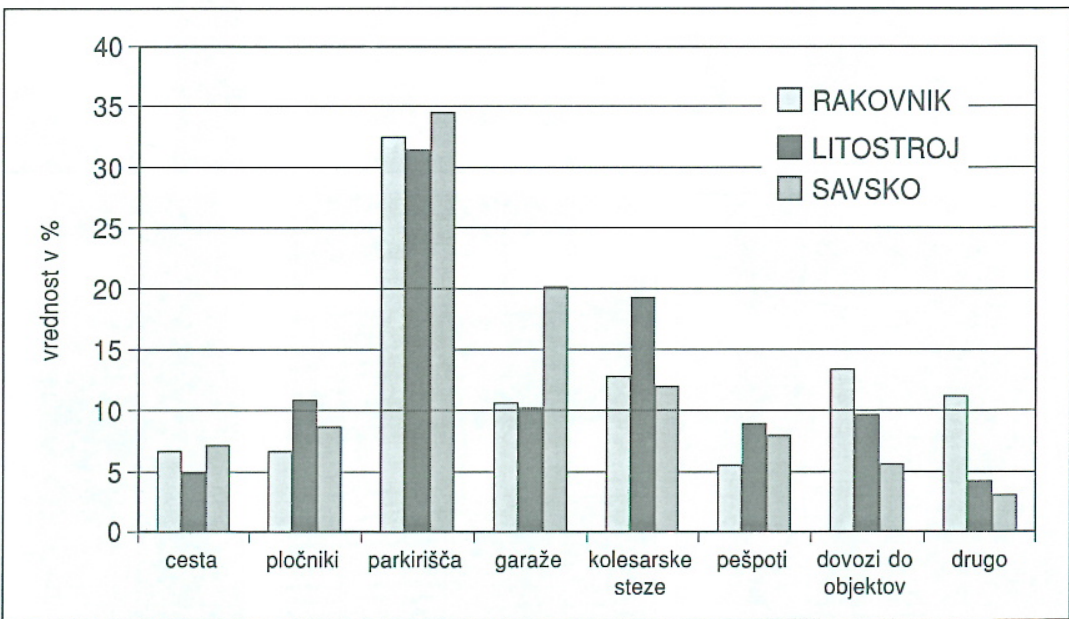

Slika 3: Analiza bivalne kulture v izbranih stanovanjskih območjih (Ljubljana: Litostrojski bloki, Savsko naselje, Rakovnik - urejenost prometnih površin, potrebna prenova objekta s stališča uporabnikov) (Vir: op. 1) 
uravnati raven kakovosti zraka - čistost, temperaturo, vlažnost), zmanjšati porabo energije oziroma preusmeriti k ekološkim energetskim virom in izboljšati opremljenost.

K navedenim ciljem je mogoče prispevati z naslednjimi ukrepi (na ravneh objektov, grajenih kompleksov, javnega prostora oziroma degradiranega območja kot celote):
- postavitev novih elementov zaščite pred hrupom (objekt, stena, zelenje, nasip);

- reorganizacija oziroma preoblikovanje materialnih komunikacij;

- obnova oziroma dopolnitev komunalne infrastrukture;

- oblikovanje prostorskih poudarkov oziroma potencialnih vozlišč aktivnosti;

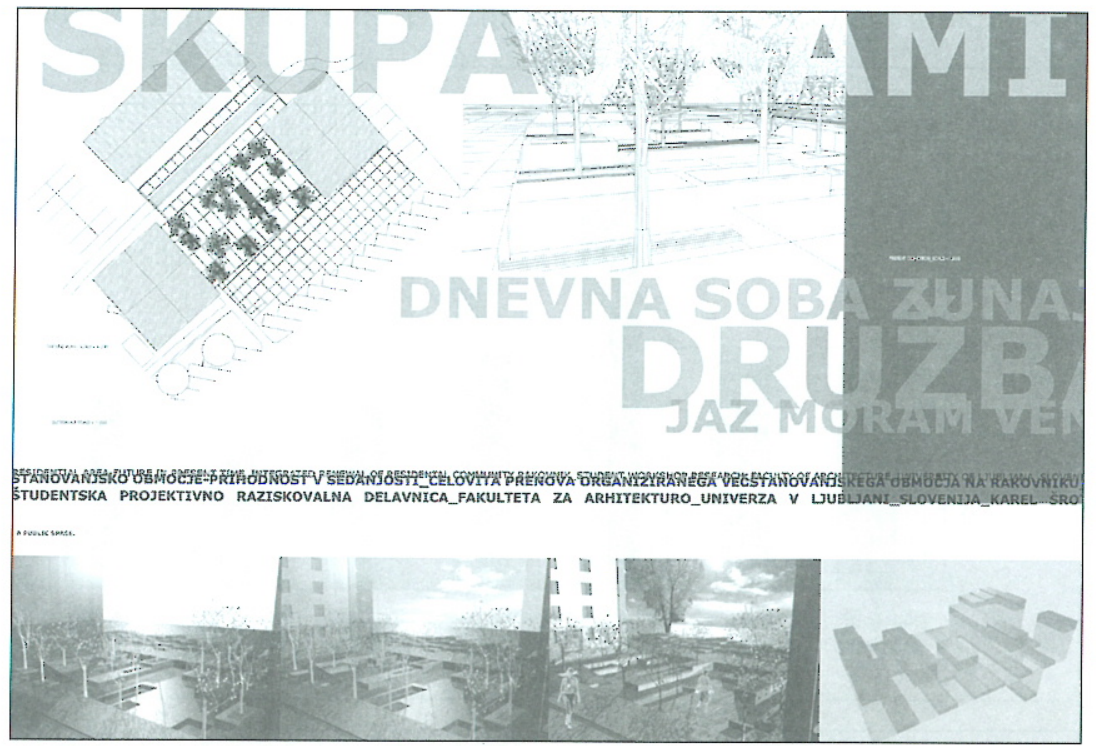

- strukturiranje skupnih zunanjih prostorov;

- sprememba zazidalne strukture (npr. zgostitev, redčenje);

- reorganizacija funkcionalne zasnove objekta(-ov);

- ojačitev konstrukcije oziroma dodatni konstrukcijski sistemi;

- sprememba obsega oziroma kakovosti likovnih in tehničnih elementov lupine stavbe oziroma stanovanja;

- vgraditev aktivnih solarnih sistemov;

- (pre)oblikovanje urbane opreme in mikroarhitekture;

- povečanje količine oziroma pestrosti elementov narave;

- uvedba sistema ločenega zbiranja odpadkov.

Prednost ciljev je treba določiti lokalno - izhajajoč iz ocene konkretnega stanja obravnavanega prostora. Ne glede na to so najpomembnejši cilji povečanje varnosti, ugodja v prostoru - ob hkratnem zmanjšanju porabe energije - in prilagodljivosti spremembam. Razmislek o
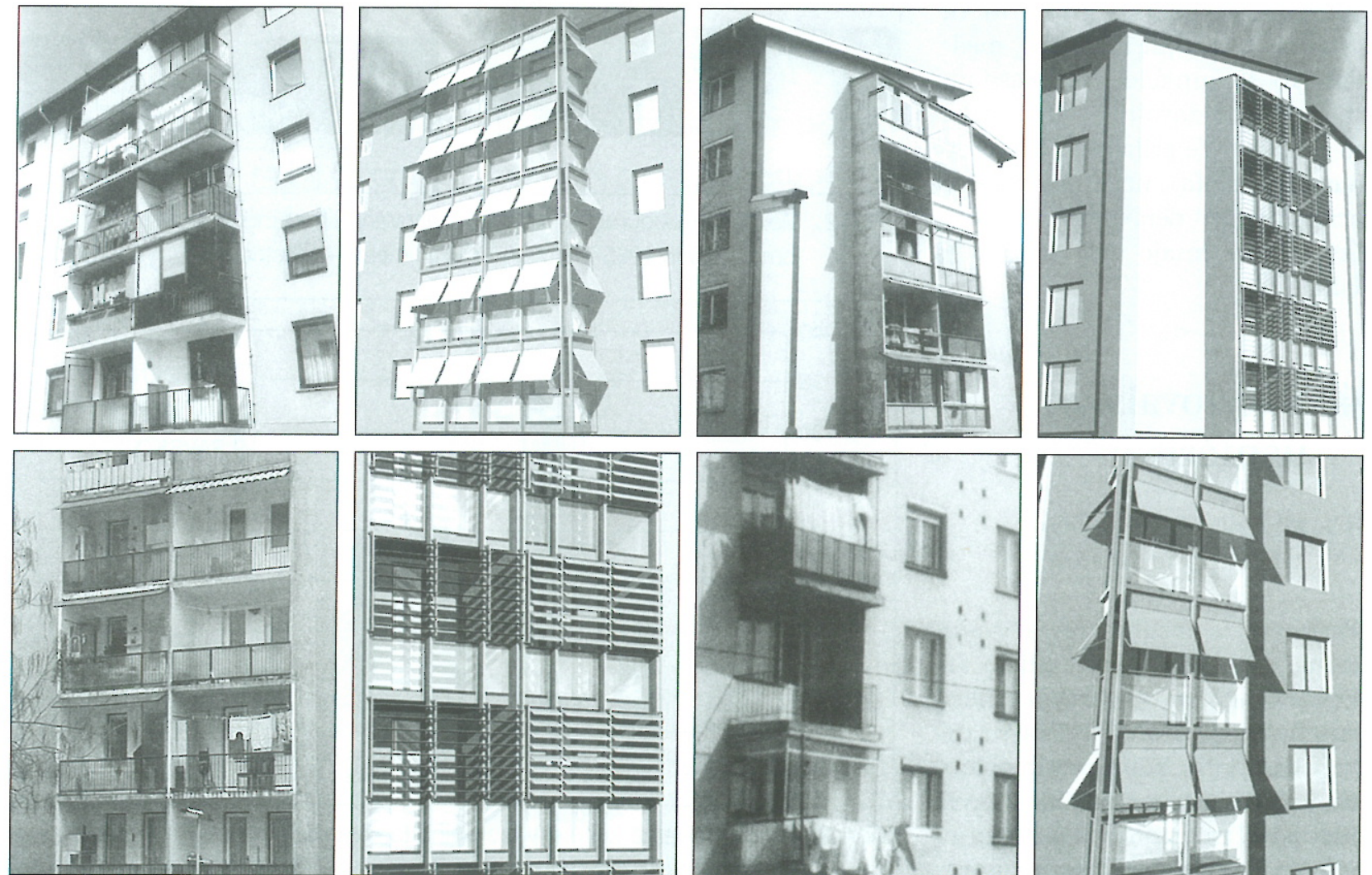

Slika 4: Preiskus prenove organiziranega stanovanjskega območja (Ljubljana: Rakovnik) (vir: op. 4) 
pomenu ukrepov za doseganje posameznih ciljev odpira vprašanja medsebojne zaporedne povezanosti ${ }^{\circ}$ ukrepov (npr. zgostitev zazidave zahteva tudi dopolnitev komunalne infrastrukture) ali možnega vzporednega izvajanja (npr. ojačitev konstrukcije lahko sproži spremembo obsega oziroma kakovosti elementov lupine stavbe, ki spremenijo zasnovo in/ali podobo prostora). V preglednici so poudarjeni ukrepi, katerih izvajanje bistveno prispeva $\mathrm{k}$ posameznim ciljem.

\subsection{Temeljni kriteriji upravičenosti prenove}

Aplikativni preiskus na območju Rakovnika v Ljubljani [4] potrjuje upravičenost prenove obravnavanih območij: stroški prenove so manjši od stroškov novogradnje, dodatek tretjine ekonomske vrednosti stanovanjskih površin pri iskanju ravnovesja med količinskimi in kakovostnimi načrtovalskimi kriteriji omogoča doseganje dva- do trikratne izhodiščne ekonomske vrednosti. Oblikovanje razvojnih usmeri-

\begin{tabular}{|c|c|c|c|c|c|c|c|c|c|c|c|c|c|}
\hline 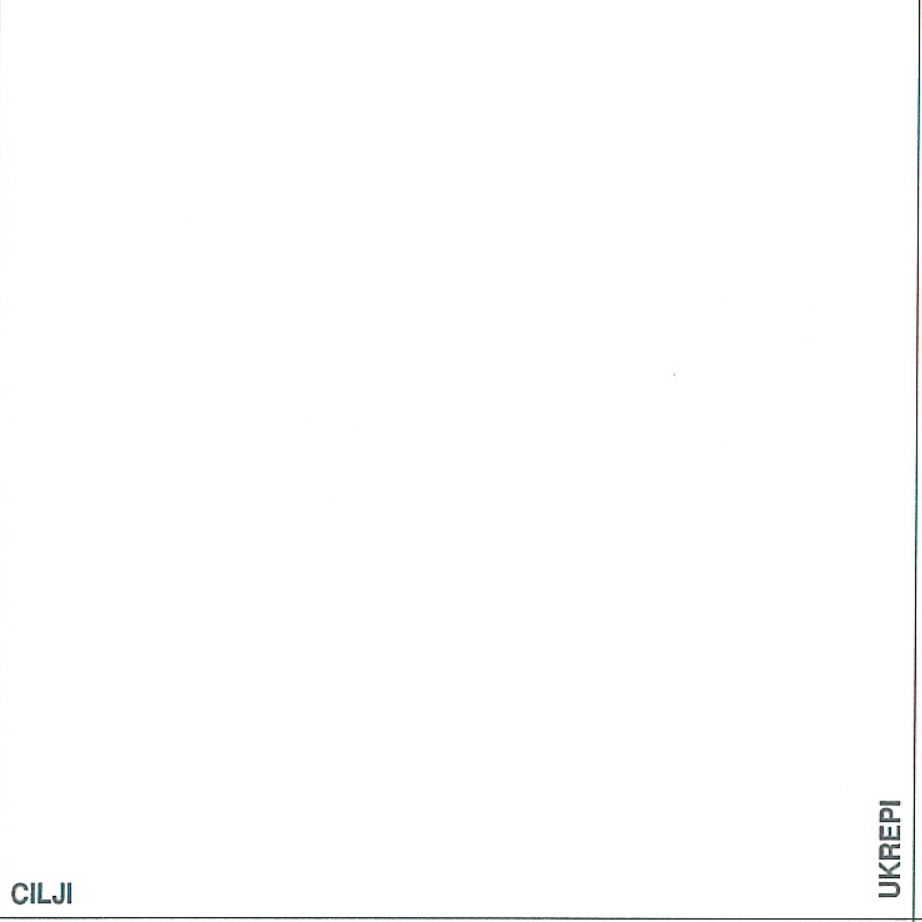 & 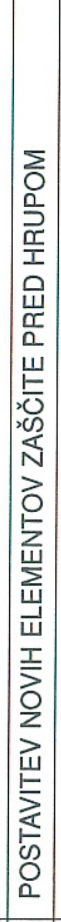 & 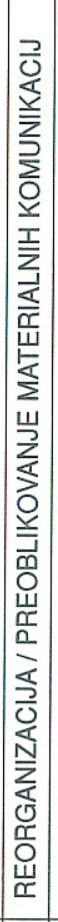 & 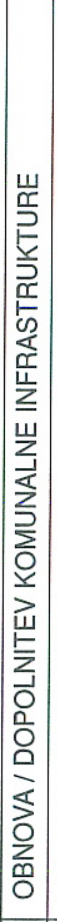 & 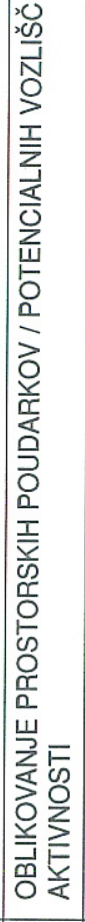 & 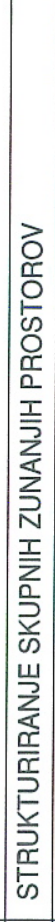 & 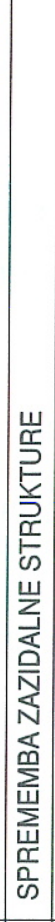 & 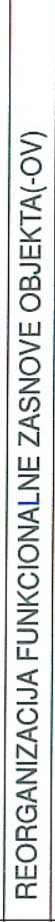 & 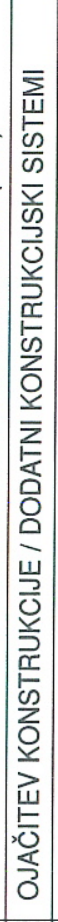 & 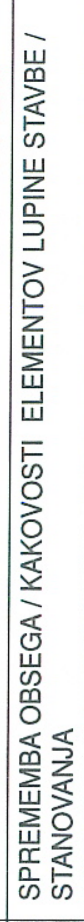 & 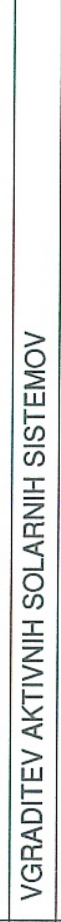 & 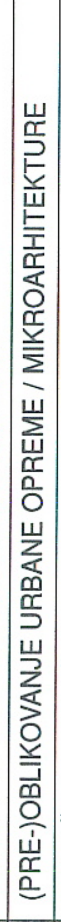 & 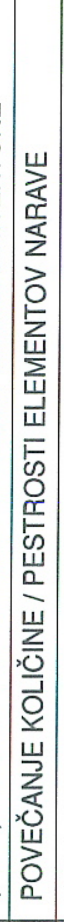 & 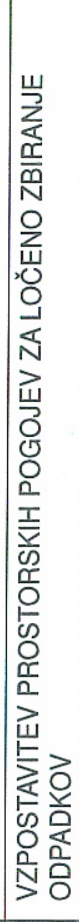 \\
\hline ohranitli / spremeniti ZASNOVO / PODOBO & & 0 & & 0 & & 0 & & & & & & & \\
\hline - poudariti HIERARHIJO > povečati RAZPOZNAVNOST & & & & O & & & & & & & & & \\
\hline izboljšati DOSTOPNOST & & 0 & & & & & & & & & & & \\
\hline - povečati UDOBJE GIBANJA & & O & & & & & & & & & & & \\
\hline izboljšati KOMUNALNO OPREMLJENOST & & & 0 & & & & & & & & & & \\
\hline izboljšatii PONUDBO BLAGA IN STORITEV & & & & 0 & & & & & & & & & \\
\hline povečati PRILAGODLJIVOST SPREMEMBAM & & O & & & & 0 & O & & & & & & \\
\hline - povečati FLEKSIBILNOST / ADAPTABILNOST ZASNOVE & & 0 & & & & & 0 & & & & & & \\
\hline - povečati M2 STANOVANJ & & & & & & 0 & & & & & & & \\
\hline izboljšati SPLOŠNO VARNOST & & 0 & & & O & & 0 & & & & & & \\
\hline - izboljšati PROMETNO VARNOST & & O & & & & & & & & & & & \\
\hline - izboljšati POTRESNO VARNOST & & & & & & & & 0 & & & & & \\
\hline uravnati nivo MIKROKLIME / UGODJA V PROSTORU & & O & & & & 0 & & & & & & 0 & \\
\hline - uravnati nivo OSVETLJENOSTI & & & O & & & 0 & & & & & & 0 & \\
\hline - zaščititi pred NEZAŽELJENIMI ATMOSFERSKIMI VPLIVI & & & & & & 0 & & & 0 & & & O & \\
\hline - ząščititi pred HRUPOM & 0 & & & & & & 0 & & & & & & \\
\hline - uravnati nivo KVALITETE ZRAKA (čistost, temperaturo, vlažnost) & & 0 & O & & & 0 & & & 0 & & & 0 & \\
\hline $\begin{array}{l}\text { zmanjšati PORABO ENERGIJE / preusmeriti K EKOLOŠKIM ENERG. } \\
\text { VIROM }\end{array}$ & & & & & & & & & O & 0 & & & \\
\hline izboljšati OPREMLJENOST & & & & & & & & & & & 0 & & \\
\hline
\end{tabular}

Slika 5: Ukrepi, ki bistveno prispevajo k ciljem arhitekturne prenove obravnavanih območij. (Vir: op. 1) 
tev temelji na specifikaciji kriterijev za upravičenost prenove kot bistvenem delu metodologije na ravni arhitekture. Strokovni vidik, ki pomeni več zavedanja potrebe po spremembah skozi čas kot uporabniški, določata kriterija višje ravni upravičenosti prenove: prilagodljivost zazidave spremembam in fleksibilnost oziroma adaptabilnost stanovanj. Izjeme so območja oziroma objekti arhitekturne oziroma mestno oblikovalske »dediščine«.

\section{Diskusija: pomen rezultatov, odprta vprašanja}

Neprilagojenost »uvoženih « prostorskih idej lokalnim razmeram botruje največjim problemom obravnavanih območij v Sloveniji. Zato je proces prenove usmerjen predvsem v ukrepe, ki povečujejo prilagojenost tako času kot kraju. Evropske primere prenove je mogoče uporabiti le v kritičnem procesu abstrakcije idej in njihove rekonkretizacije $v$ spremenjenih razmerah. Tudi razlike $\mathrm{v}$ strokovni in uporabniški oceni stanja pomenijo zavoro v iskanju možnosti za izvajanje konkretnih in učinkovitih prispevkov $\mathrm{k}$ izboljšanju kakovosti bivanja v obravnavanem poselitvenem vzorcu. Izpopolnitev metodološkega instrumentarija zato ni le prispevek k razvoju znanosti, ampak tudi za aplikacijo. Rezultate je $z$ vidika materialov in energije možno aplicirati tudi na enodružinske stanovanjske stavbe iz istega obdobja (do energetske krize s konca 70. let). Rezultati študije so uporabni za različne ravni gradbene prakse in kot spodbuda razvojnim raziskavam konkretnih lokacij.

Odprta ostajajo predvsem vprašanja racionalne stopnje kompleksnosti prenovitvenih posegov glede na njihovo medsebojno pogojenost $\mathrm{z}$ vidika možnih stopenj individualizacije (merilo območja posega, ključ- nost, faznost, nujni akterji) ter vzpostavitve sistema prenovitvenih ravni kot priložnosti za ozaveščanje o možnostih in poenostavitev odločitev o ukrepih prenove: vprašanja razmerij med ravni potrebnega obsega prenove, sposobnosti lastnikov oziroma uporabnikov za prenovo in ravni formalnih ter neformalnih stimulacij prenove.

Doc. dr. Tadeja Zupančič Strojan, univ. dipl. inž. arh.; doc. dr. Martina Zbašnik Senegačnik, univ. dipl. inž. arh.; asist. dr. Tomaž Novljan, univ. dipl. inž. arh; asist. mag. Alenka Fikfak, univ. dipl. inž. arh, Univerza v Ljubljani, Fakulteta za arhitekturo;

E-pošta: tadeja.zupancic@arh.uni-lj.si; martina.zbasnik@arh.uni-lj.si; tomaz.novljan@arh.uni-lj.si; alenka.fikfak@arh.uni-lj.si

\section{Opombe}

[1] Raziskovalna naloga (sofinancer: Ministrstvo za šolstvo, znanost in šport): Zupančič Strojan, Tadeja (ur.). Povojne stanovanjske soseske v Sloveniji: metodologija vrednotenja in prenove $=$ Post war housing estates in Slovenia: methodology of evaluation and renewal. Ljubljana: Fakulteta za arhitekturo; Dunaj: Technische Universität Wien, 2002. 288 str., ilustr. [COBISS.SI-ID 1338756]. Soavtorji posameznih poglavij: Tadeja Zupančič Strojan, Martina Zbašnik Senegačnik, Tomaž Novljan, Alenka Fikfak, Edo Wallner (UL, FA), Andreas Voigt, Hans Peter Walchhofer, Rainer Mayerhofer (TU Wien), Konzultantka: Živa Kristl (UL, FGG).

[2] Meade, M., 1997: Lyons renewal Quartier des Gratte - Ciel. Architectural Review 1207, 73-77; Uhrig, N., 1998: Quartier-Pavillon Berlin - erst blau, dann grau. Topos 22, 81-86; Machule, D., Scholz, M., 1991: Onkel Tom Siedlung in Berlin Zehlendorf. Bauwelt 44, 2330-2334; Fassadensanierung in Dresden. Detail 4/1998, 611-614.

[3] Študentska raziskovalna naloga: Proučevanje in načrtovanje mikrourbanega okolja, zasnova: prof. dr. France Rihtar, doc. dr. Tadeja Zupančič Strojan; Univerza $\vee$ Ljubljani, Fakulteta za arhitekturo. $V$ nalogi, ki je zajemala primerljiva območja po Sloveniji, je v letu 2002 sodelovalo sto trideset študentov. Primer: Vovko, Mitja, Prešeren, Robert: Novo mesto - Mestne njive. 4 Urbanističnoarhitekturna delavnica: Gantar, Irena,
Gortnar, Vanja, Hudobivnik, Petra, Kremžar, Nika, Novina, Miha, Šrot, Karel, Uršič, Alenka, Vanič, Jure; Trošt, Jan (vizualizacija); mentor: Gabrijelčič, Peter, somentorji: Fikfak, Alenka, Novljan, Tomaž, Zbašnik Senegačnik, Martina, Zupančič Strojan, Tadeja; konzultanti: Drčar, Jože (protipotresna sanacija), Vrevc, Cirila (izračun stroškov), Kristl, Živa (toplotni izračun). Stanovanjsko območje - prihodnost v sedanjosti: celovita prenova organiziranega stanovanjskega območja na Rakovniku: študentska projektivno-raziskovalna delavnica. Ljubljana: Fakulteta za arhitekturo, 2002. 1 el. optični disk (CD-ROM). [COBISS.SI-ID 24239365]

\section{Literatura}

Abel, C. Architecture as Identity, Towards a Global Eco-culture. Oxford, Boston, Johannesburg, Melbourne, New Delhi, Singapore: Architectural Press, 1997.

Brezar, V., Kalčič, I. Družbeno usmerjena stanovanjska gradnja v Sloveniji, koncept, tloris, raba, (Arhitektura), (Stanovanjsko in komunalno gospodarstvo). Ljubljana: RSS, 1986. 33 str., ilustr.

Croci, G. The conservation and structural restoration of architectural heritage, Advances in architectural series, Computationa mechanics publications, Southampton, UK, 1998.

Dimitrovska Andrews, K., Sendi, R., Jarc, D., Cotič, B., Pichler Milanović, N., Černič Mali, B., Dalla Valle, S. Kriteriji in metode kompleksne prenove velikih sosesk: mednarodne primerjave in izhodišča za Slovenijo. 1. faza, Primerjava metod kompleksne prenove stanovanjskih sosesk $v$ tujini in razvoj ogrodja za ocenjevanje učinkovitosti posameznih metod. 2. faza, Velike stanovanjske soseske v Sloveniji: stanje, problemi in možnosti prenove, 3. faza, Revitalizacijsko ogrodje kompleksne prenove stanovanjskih sosesk. Ljubljana: Urbanistični inštitut Republike Slovenije, 1999.

Dimitrovska Andrews, K., Sendi, R. Large housing estates in Slovenia : framework for renewal. European journal of housing policy, 2001, vol. 1, no. 2, 233-255.

Brezar, V. The vicious circle of develepment in housing. Int. j. hous. sci. appl., 2001, vol. 25, no. 3, str. 157-172, ilustr.

Fajfar, P. Projektiranje potresno varnih konstrukcij ob upoštevanju dejanske nosilnosti in duktilnosti. Ljubljana: FAGG, Inštitut za konstrukcije, potresno inženirstvo in računalništvo, 1994.

Fajfar, P. Nova metoda za ocenjevanje potresne varnosti in poškodovanosti konstrukcij / Gradbeni vestnik, 1995, 4/5/6, str. 88-93. 
Fister, P., Deu, Ž., Graham, R. E, Lah, L., Likar, D, Marinko, J, Molek, L. Celostno varstvo stavbnih in naselbinskih vrednot $v$ prostorskem razvoju. Strokovne podlage za prostorski plan Slovenije - sistem poselitve; v tisku. Ljubljana: Univerza v Ljubljani, Fakulteta za arhitekturo, 2001.

Gabrijelčič, P. , Fikfak, A., Zavodnik, A., Šolar, L., Lenart, M. Urejanje prostora z vidika razpršene gradnje, raziskovalna naloga na FA, prvo in drugo fazno poročilo za MOP, Urad RS za prostorsko planiranje, 1995.

Greed, C., Roberts, M. (ur.). Introducing Urban Design. Essex: Addison Wesley Longman Limited, 1998.

Kilar, V., Krstulovič - Opara, N. Seismic behavior of a high-performance composite frame building made with advanced cementitious composites. V: Singh, Amarjit (ur.). Creative systems in structural and construction engineering. Rotterdam; Brookfield: A. A. Balkema, 2001, str. 749-754.

Koselj, N.. Arhitektura 60. let $v$ Sloveniji $=$ ŠArchitecture of the 60ies in Slovenia: kontinuiteta ideje, (Posebna izdaja, letn. 25 nov. 1995). Ljubljana: AB, 1995

Koželj, J. Degradirana urbana območja. Ljubljana: Ministrstvo za okolje in prostor, Urad RS za prostorsko planiranje, 1998.

Kraft, S. La dinamica delle citta, Europan 3: A casa in citta, urbanizzare e quartieri residenziali; concorsi europei per nuove architetture, risultati europei; CER, comitato per l'edilizie residenziale, 1994.

Kristl, S. Stanovanjske stavbe II. Ljubljana: Univerza v Ljubljani, Fakulteta za arhitekturo, 1991.

Mlinar, Z. Individualizacija in globalizacija v prostoru. Ljubljana: SAZU, 1994.

Rihtar, F., Zupančič Strojan, T. Prostor mesta. Ljubljana: Univerza v Ljubljani, Fakulteta za arhitekturo, 1996.

Tomaževič, M., Klemenc, I., Lutman, M. Strengthening of existing stone - masonry houses: lessons from the earthquake of Bovec of April 12, 1998. European earthquake engineering, 2000 , vol. 14 , no 1 , str. 13-22

Tomaževič, M. Reduction of seismic risk of existing buildings in earthquake-prone cities: experience of Ljubljana. V: Technology and culture as a basis for urban development : Ljubljana 100 years after the earthquake: summaries. Ljubljana, 1995.

Turkington, R., Wheelaghan, S. The refurbishment of high-rise local authority housing blocks: involving the tenants:lessons from the UK. Urbani izziv, 1995, 28-29, p. 40-45.

Vodopivec, Aleš. Paradigme 60 . let. $A B=$ ISSN 0352-1982. Let. 27, št. 137-138 (november 1997), str. 32-36.
Nataša PICHLER MILANOVIĆ

\section{URBS PANDENS - Ali kako se ukvarjati s posledicami (ne)načrtnega širjenja mestnih območij v združeni Evropi

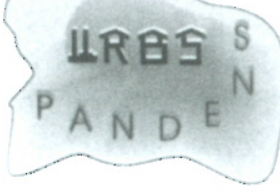

Urban sprawl je novi fenomen $\mathrm{v}$ razvoju evropskih mest in ena od najpomembnejših sprememb rabe prostora $\mathrm{v}$ drugi polovici 20. stoletja v Evropi. Proces širjenja mestnega območja je posledica razraščanja zazidanih površin oziroma pospešene gradnje novih ali razširitev zdajšnjih prometnic, prostostoječih enodružinskih, vrstnih ali večstanovanjskih hiš, velikih nakupovalnih središč, lokalnih industrijskoobrtnih con ter drugih oskrbnih središč na obrobju mesta ali na območju sklenjenega mestna, ki pa neposredno vplivajo na klimatske spremembe na globalni ravni in zmanjšujejo kakovost življenja na lokalni ravni. Pri prevodu ameriškega izraza urban sprawl obstaja terminološka nejasnost, saj ne po-

meni samo razpršene poselitve, ampak tudi zgoščeno. Suburbanizacija je samo del procesa in ni več ustrezen izraz za pojav. Mišljeni so predvsem nenadzorovano razraščanje zazidanih površin (npr. na račun kmetijskih površin ali odprtega prostora), neučinkovita raba prostora (npr. nizke gostote poseljenosti in visoka cena komunalne opremljenosti) in s tem povezana degradacija okolja (npr. emisije nevarnih snovi, poplave, kakovost pitne vode, fragmentacija ekosiste$\mathrm{ma}$ ), diferenciacija $\mathrm{v}$ bivalnem in delovnem okolju (npr. segregacija, revščina, kriminal, brezposelnost itn.). Te nevarnosti v razvoju mest, njihova medsebojna sinergija in nasprotujoči si interesi pri njihovem razreševanju so skupen izziv v

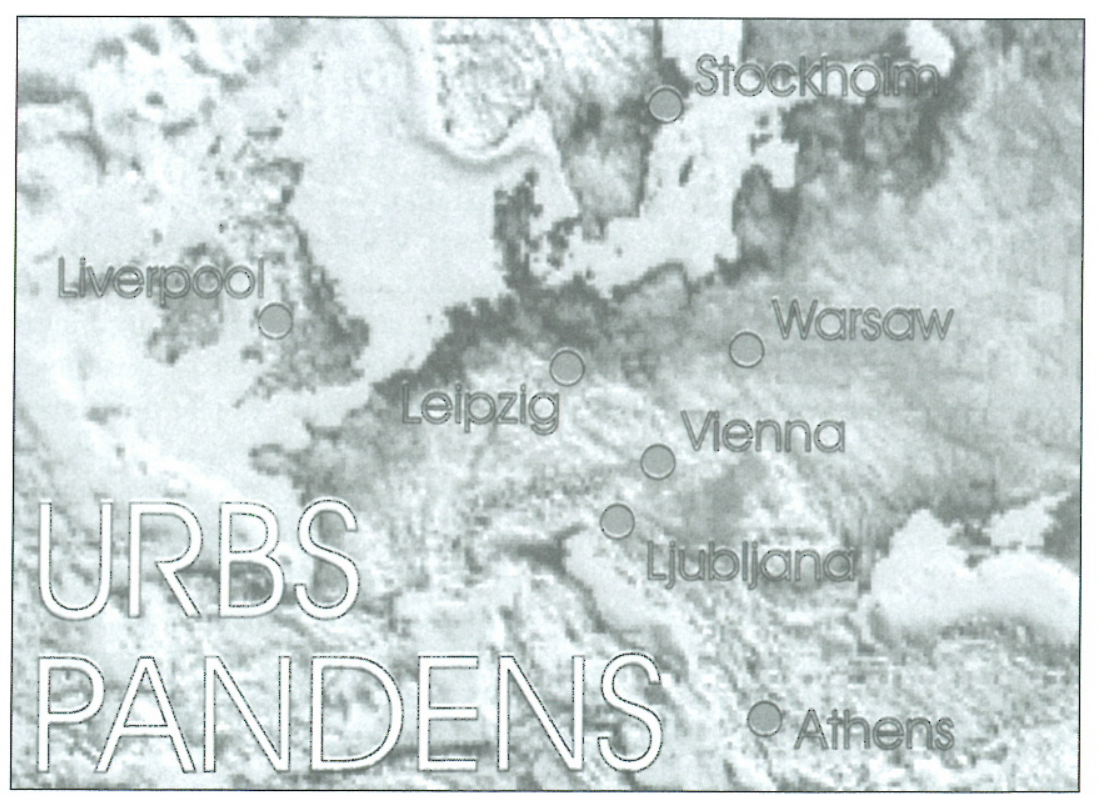

